\title{
Orientação do trabalho colaborativo na construção do saber docente: a perspectiva do planejamento coletivo do trabalho pedagógico $(\mathrm{PCTP})^{1}$
}

\begin{abstract}
Resumo: Este estudo busca descrever a construção de algumas ações orientadoras na construção de um trabalho coletivo do interior de um projeto de formação continuada para professores de educação física na rede pública de ensino de Uberlândia-MG denominado Planejamento Coletivo do Trabalho Pedagógico (PCTP). A metodologia é caracterizada como um estudo de caso do tipo etnográfico. O estudo aponta que sendo a construcão de saber, através de um processo colaborativo, uma dimensão social esta se materializa a partir de intercâmbios intersubjetivos e discursivos sendo necessário uma interlocução irrestrita com as diferentes vozes que fazem parte do processo. Palavras-chave: Saber Docente, Trabalho Coletivo, Formação Profissional.
\end{abstract}

Este artigo trata de descrever e analisar as orientações do trabalho coletivo no interior de um processo de formação continuada para professores de Educação Física que vem sendo desenvolvido na cidade Uberlândia pelo Nepecc/UFU desde 1993 junto a Escola de Educação Básica da Universidade Federal de Uberlândia (ESESA/UFU) e na Rede Municipal de Ensino (RME) desde 1996, denominada de Planejamento Coletivo do Trabalho Pedagógico (PCTP).

\footnotetext{
Professora Adjunto da Faculdade de Educação Física da Universidade Federal de Uberlândia-MG e coordenadora do Núcleo de Estudos em Planejamento e Metodologias de Ensino da Cultura Corporal (NEPECC/UFU).

1 Este texto faz parte de algumas reflexões contidas em minha tese se doutorado denominada: "La construcción dei saber docente de profesores de Educación F́́sica: los campos de vivência", apresentada em janeiro de 2004 no Departamento de Didática e Organização Educativa da Universidade de Barcelona/Espanha sob a orientação do Dr. Serafín Antunez Marcos.
}

Movimento, Porto Alegre, v. 10, n. 1, p. 157-179, janeiro/abril de 2004 
Este se caracteriza como uma estratégia crítica de intervenção político-pedagógica que foi progressivamente implementada e sistematizada durante o processo de assessoria para a elaboração e implementação de uma proposta curricular para a área de educação física escolar. O esforço de sistematização deste processo é produto da necessidade de dar identidade ao trabalho desenvolvido buscando sua legitimação no currículo escolar (Munoz Palafox, 2001). ${ }^{2}$

Neste sentido, discutir aqui algumas orientações contidas neste processo de formação continuada passa a ser relevante na medida em que este coletivo continua sustentando, no seu interior, princípios éticos-políticos dentro de uma perspectiva de trabalho colaborativo, dimensionando assim o olhar para uma formação profissional, para a autonomia e participação crítica.

$\mathrm{O}$ trabalho aqui apresentado se fundamentou em uma perspectiva qualitativa tendo como metodologia o estudo de caso do tipo etnográfico realizado com três professores que participam deste coletivo.

A idéia de coletivo aqui é entendida como uma experiência histórica de um grupo para o qual o trabalho coletivo tem algum sentido (Gadotti, 1987). Assim que, o entendimento de coletivo não deve estar sujeito somente a uma reunião de pessoas em torno de um determinado assunto e sim a partir da necessidade de dar sentido as coisas, tendo uma "objetividade, uma perspectiva colocada frente ao grupo que somente poderá ser alcançada se o trabalho de fato se realiza em conjunto" (Terra, 1997, p. 217).

Entretanto, desenvolver um trabalho colaborativo que se propõe desde uma dimensão coletiva, onde o diálogo irrestrito entre os participantes é uma das principais diretrizes para uma prática crítica comprometida com a melhora do ensino e da formação profissional, representa ter presente os conflitos e os elementos de orientação na construção do saber no coletivo.

2 Para maior conhecimento deste processo de formação continuada e do contexto do PCTP ver nesta mesma revista os artigos de Gislene Alves do Amaral e de Gabrie Humberto Munoz Palafox.

3 Neste artigo os nomes dos participantes foram substituídos por Josep, Núría e Llüisa no qual o leitor poderá acompanhar as declarações dos mesmos.

Movimento, Porto Alegre, v. 10, n. 1, p. 157-179, janeiro/abril de 2004 
Para os professores participantes do estudo, estes elementos estão identificados como: o processo de registro chamado "ajuda memória", a organização coletiva na escola e a argumentação como critério de validade do saber. Estes, trabalhados dialeticamente no coletivo através da reflexão e do diálogo, podem gerar, segundo Elliott (1990), formas compartilhadas de compreensão das concepções éticas e das contradições da prática.

\section{"Ajuda Memória": o registro como processo de formação profissional}

As "Ajuda Memória" constituem uma prática estabelecida nas reuniões onde se registram os fatos ocorridos na mesma. Esta é realizada em cada reunião por um ou mais professores. Como alguns* professores não se sentem seguros para desenvolver esta tarefa, se orienta que para que possam desenvolver em conjunto com aquele que já tem a experiência. Ninguém está obrigado a participar na construção do relato, este é feito por aqueles que desejam e de uma maneira geral se vai estimulando a participação de outros, orientando aqueles que tem mais dificuldade para utilizar como estratégia a gravação da reunião.

O informe do registro sempre é lido pelo grupo no início da reunião seguinte, algumas vezes, dependendo das condições estruturais se envia antecipadamente. As reuniões normalmente iniciam com a leitura do registro, com o objetivo de: orientar aqueles que não estavam presentes na reunião anterior sobre o contexto do debate; eliminar dúvidas das discussões e deliberações; e recuperar as informações para dar continuidade às decisões.

O registro não tem uma forma específica, ou seja, um modelo predeterminado. Por isso, existem registros realizados de características diferentes, mas sem perder a idéia central que é de fazer um relato da realidade vivida no coletivo. Para os professores, reproduzir esta realidade coletiva é permitir analisar como progredir no debate sobre as temáticas que o grupo vai apresentando, pois segundo Llüisa, é comum, quando não se tem a prática de atuar com o trabalho coletivo, ficar dando voltas nas coisas e caminhar pouco. 
A idéia da Ajuda Memória é para que nossa história não se perca e também para orientar nossas ações. Este processo é interessante porque algumas vezes nos damos conta de questões que já haviam sido apresentadas e que não foram percebidas. Com o registro se pode verificar o contexto no qual as coisas foram ditas e reflexionar com mais profundidade nos diferentes momentos nos quais elas aparecem. Assim, damos poucas voltas nas coisas, pois como está registrado, o grupo percebe que algo não foi muito bem, mas é importante verificar o por quê.

Durante o trabalho de campo pude presenciar um fato como o que declarou Llüisa. O grupo, no final de 2001, percebeu que o Plano Básico de Ensino $(\mathrm{PBE})^{4}$ necessitava ser reestruturado, e colocaram esta tarefa na agenda de 2002. Entretanto, em agosto deste mesmo ano, pelo motivo da construção do Simpósio de Estratégia de Ensino, ${ }^{5}$ identificaram que a tarefa não havia começado a ser desenvolvida. Neste sentido, o grupo, sem apresentar nenhuma frustração, avaliou as circunstâncias e concluiu que as dificuldades estavam relacionadas, principalmente, por duas questões: a extensa greve, no primeiro semestre de 2002, do setor público federal que afetou a Eseba, e também a greve de um pouco mais de trinta dias na prefeitura que culminou com o retorno da Eseba; e a novidade de trabalhar conjuntamente as duas instituições: Prefeitura e Eseba.

Para Josep, o registro possibilita caminhar com mais segurança, e perceber, sem medo de erros, as análises e reflexões realizadas. Além disso, possibilita reconhecer determinados equívocos e, ou melhor, identificar o onde? e o porque?, para assim, progredir com mais confiança. Para este professor

Como ninguém é perfeito, também nos equivocamos em nossos argumentos e decisões realizadas. Não é que o registro vai te denunciar ou condenar, mas vai te orientar e tu tem a oportunidade de refletir sobre as ações do grupo para, quem sabe, voltar a dar um passo mais firme da próxima vez.

4 O PBE significa o conjunto de diretrizes de uma proposta curricular pensada para construir a identidade da área. Para maior profundidade do tema ver o artigo de Gislene Alves do Amaral nesta revista.

5 O Simpósio de Estratégia de Ensino é um espaço alternativo de trabalho e estudo que busca promover a sistematização das reflexões e das estratégias implementadas e avaliadas coletivamente entre os professores, vislumbrando a perspectiva objetiva de mesmo autor nesta revista.

Movimento, Porto Alegre, v. 10, n. 1, p. 157-179, janeiro/abril de 2004 
No trabalho de campo participei na elaboração de algumas "Ajuda Memória" junto com os professores quando se estava discutindo a reelaboração do PBE e a construção do simpósio de estratégias de ensino. Pude perceber que a dinâmica, além de facilitar, orientava o debate e possibilitava avançar nas discussões em cada reunião. $\mathrm{O}$ registro, materializado na escrita, permitia fazer criticas sobre as próprias decisões que se havia tomado e isto é importante, pois poder fazer esta reflexão e voltar a debater e definir uma e outra vez é um aprendizado que, no meu entender, está sempre sendo elaborado por um novo saber que o professorado registra.

Analisando as "Ajuda Memória", que tive acesso durante o trabalho de campo e aquelas que fui recebendo até o final do informe da pesquisa, foi possível identificar também o movimento do cpletivo. Minha percepção é que o grupo, nos dois últimos anos, teve uma dificuldade, no início do ano, para se articular e para dar continuidade ao trabalho que foi estabelecido na última reunião antes das férias. Entretanto, encontrei estas dificuldades somente naquelas reuniões do coletivo amplo, onde estiveram presentes as três instituições (Eseba, Prefeitura e Universidade). As reuniões internas das instituições aconteciam com mais normalidade e continuidade.

Sendo uma novidade a unificação das três instituições nesta dinâmica de trabalho, o grupo, passado um ano, todavia não se tinha encontrado um ponto de articulação que permitisse uma trajetória mais efetiva em uma ação que seria prioritária para a reestruturação do PBE. A interpretação que faço deste fato é que os professores alcançaram um grau de autonomia mais centrada em suas próprias instituições, e o que faltava era construir esta relação unificada, de maneira que o coletivo pudesse se reunir para concretizar um PBE que de fato fosse coletivo, já que eles mesmos manifestaram esta necessidade e relevância para a educação física na cidade.

Voltando ao processo de elaboração da Ajuda Memória considero que esta forma de construir o saber coletivo foi um desafio para grupo que não vê o registro como um instrumento de caráter burocrático e legalista de uma ata de reunião. Representa um instrumento orientador do caminho percorrido pelo trabalho coletivo. Registrar e debater as ações coletivas no interior do grupo é propor um tipo de relação entre professorado, de caráter participativo, deliberativo e comprometido. E mais, neste 
"campo de vivência" ${ }^{6}$ o professorado matiza (re) elabora e organiza seus saberes, já que no registro se documenta o esforço e o tipo de leitura que o coletivo faz da realidade para intervir nela.

\section{Organização coletiva na escola}

Para os professores, o trabalho coletivo tem uma função muito significativa nesta experiência, pois, basicamente, todas as ações e decisões advindas do coletivo contribuíram para que o trabalho na escola caminhasse de maneira satisfatória.

O fato de compartilhar a maneira de dar aula, como as preparavam, como tomavam decisões frente aos alunos a partir de uma determinada atitude, como avaliavam, e até mesmo como reagiam frente a algumas questões político-administrativas, possibilitou a vários grupos, organizados coletivamente nas escolas, construir sua identidade profissional, as diferentes maneiras de olhar a profissão, o ensino e eles mesmos, ampliando assim sua inserção, imersão e compromisso no mundo educacional. Segundo a declaração de Alves et ai. (2002, p. 151), quando descrevem suas experiências de trabalho coletivo na escola:

Ao longo dos anos conseguimos mostrar a identidade da Educação Física que defendemos, adquirimos nossos espaços como profissionais, temos uma certa inserção na comunidade escolar e estamos sempre a frente na luta por uma escola democrática, autônoma e de qualidade, seja no âmbito escolar ou nas lutas sindicais. O grupo reconhece, valoriza e enfatiza o trabalho coletivo, pois acreditamos que para conseguirmos as transformações sociais que desejamos, é preciso com muito estudo e crescimento profissional.

Para os professores, o trabalho coletivo na escola é uma experiência interessante pelo fato de poder planejar com um grupo pequeno e discutir coisas mais específicas de seu entorno. Normalmente existem muitos problemas na escola que de maneira geral parecem não ter grande importância, mas que influenciam o bom andamento das atividades entre os próprios professores.

Como exemplo posso citar o problema da distribuição do espaço físico e do material para as aulas que Llüisa tinha em umas das escolar onde trabalhava. Segundo a professora, na escola

6 Os Campos de Vivência significa os diversos espaços onde os professores se organizam coletivamente para debaterem e construírem suas atividades pedagógicas e profissionais. Ver nesta revista os artigos de Gislene Alves do Amaral e Gabriel Humberto Muñoz Palafox.

Movimento, Porto Alegre, v. 10, n. 1, p. 157-179, janeiro/abril de 2004 
onde os professores atuavam coletivamente no planejamento, este problema não existia, pois se organizava as tarefas de acordo com o espaço e material, existente mesmo que não fosse fácil no início, pois nenhum professor se sentia prejudicado, já que manter o acordo defino pelo grupo era fundamental. Llüisa conta que

Nós planejávamos tudo, desde a distribuição do conteúdo até o espaço físico para todo o ano e isso facilitava muito a vida junto aos alunos e a tua própria organização. Trabalhar em uma escola assim foi uma experiência incrivel, pois naquelas onde não existe este tipo de prática ia trabalhar com aquela angústia de poder brigar a qualquer momento por um problema de material ou de espaço fisico, isso desgasta muito e te tira a vontade ponco a pouco de ir naquela escola, pois tudo é problema.

As declarações de Llüisa podem ser confirmadas em outras experiências de trabalho coletivo no espaço escolar, como por exemplo a de Silva et al. (2002, p. 96) sobre a organização do material e espaço físico e a influência num bom desenvolvimento das atividades entre o grupo de professores. As autoras afirmam que, "segundo nossa avaliação, a organização do trabalho favoreceu um melhor aproveitamento do tempo e do espaço escolar e propiciou uma maior sintonia entre as professoras (...), principalmente no que se refere a divisão do material utilizado nas aulas de práticas

O professorado está convencido de que a criação de estruturas que valorizem a organização do tempo e do espaço do professor não se resume apenas nesse aspecto específico da aula, mas também proporciona uma maior discussão do processo de formação para uma aprendizagem do trabalho coletivo.

Os professores reconhecem que existem muitas dificuldades no interior das escolas para construir trabalhos coletivos entre a própria área, já que inicialmente a pessoa tem que querer, apesar de que a experiência vem demonstrando que o querer é também um processo de aprendizagem social e por isso mesmo pode ser construído. Considerando que esta construção coletiva acontece através de um processo de interação comuni-cativa entre os participantes, para que Habermas (1989a), é a via pela qual os homens se interrelacionam socialmente entre si por meio de diferentes expressões da linguagem articuladas, quer dizer, a capacidade discursiva argumentativa entre as pessoas, vejo que quanto espaços coletivos forem criado, maior pode ser a inserção do professorado em um projeto coletivo.

Movimento, Porto Alegre, v. 10, n. 1, p. 157-179, janeiro/abril de 2004 


\section{Argumentação: o discurso coletivo na construção do saber}

Discutir e registrar a prática representa refletir e analisar a realidade. É debatendo sobre a realidade que a pessoa revela suas concepções através dos argumentos apresentados sobre um determinado tema. Além disso, é no interior deste debate que segundo Gauthier et al. (1998) se constrói o saber. Significa que o saber acontece também em função do ângulo discursivo, argumentativo e comunicativo que as pessoas são capazes de chegar a uma saber comum. Habermas (1989b, p. 481) chama saber comum aquele "saber que finca acordos, sendo que tal acordo constitui o resultado de um reconhecimento intersubjetivo de pretensões de validez susceptíveis de crítica. Acordo significa que os participantes aceitam um saber como válido, quer dizer, como intersubjetivamente vinculado".

O professorado, quando fala das relações internas entre o grupo, vai reconhecendo que não é fácil, existem conflitos que nem sempre são fácies de resolver, mas buscam entender as dificuldades e limitações do outro e ter paciência para que as pessoas aos poucos possam compreender que as conquistas até o momento foram possíveis pela insistência de trabalhar coletivamente. Segundo Llüisa

No trabalho coletivo conhecer e entender o outro é fundamental, não é que seja uma maneira que todo se justifica, mas tu vai dando conta de coisas e vai sabendo como deves relacionar-se com as diversas pessoas. Somente se pode construir alguma coisa quando o grupo cria debates e toma decisões provocadas pelo diálogo.

Para Núria e Josep, que possuem uma experiência conjunta na mesma escola, somente foi possível superar os problemas no coletivo e avançar com uma proposta para a educação física a base de muito diálogo interno, as vezes um pouco duro, mas necessário. Hoje, participam em vários outros grupos de trabalho em sua escola e dizem que há professores que estão preocupados pensando que não se chagará a nenhum lugar. Entretanto, Núria e Josep, identificam este momento com o que eles passaram no inicio dessa experiência com a área e dizem as vezes parece que estamos vendo passar um filme que já vimos. Para eles cada espaço possui um diálogo diferente porque tem uma história diferente, mas o que fazemos é colocar em prática o que aprendemos no coletivo da área e intentar ajudar.

Movimento, Porto Alegre, v. 10, n. 1, p. 157-179, janeiro/abril de 2004 
Para o professorado, em um processo de trabalho coletivo se deve estabelecer um processo de diálogo onde todas as pessoas, de fato, participem apresentando seus argumentos chegando assim, num processo de acordo. Para que o diálogo e os acordos pudessem ser estabelecidos satisfatoriamente de uma maneira democrática foram criados alguns princípios que eles determinaram político-pedagógicos, para orientar suas práticas e o trabalho coletivo. Estes foram fundamentais no início do trabalho, e sua construção significou uma profunda reflexão e um grande esforço comunicativo. Segundo Núria

Definir os principios foi um dos principais passos para uma aprendizagem coletiva. Na verdade os princípios te dão uma direção para o trabalho junto aos alunos e tua relação com os demais professores. Não são fechados e tão pouco é um guia como uma camisa de força. É um guia de reflexão que nós mesmos, dentro de nossas limitações, propusemos e que a qualquer momento pode ser revisado.

Pensando nos princípios como orientação para chegar a acordos comunicativos, Llüisa aponta que

Entrar em acordos e consensos não significa que um cede e pronto, ou aquela coisa que a maioria decidiu e ponto final. A maioria decidi, mas não existe falsa democracia para enganar a pessoas, o que se faz é garantir a fala de todos e refletir sobre os argumentos apresentados em função dos princípios orientadores que determinamos.

É neste sentido que Boufleuer (1998, p. 28) argumenta que o conceito de racionalidade comunicativa "aponta para a capacidade de ação sem coerções e produção de consensos mediante a fala argumentativa, com que os sujeitos da comunicação asseguram a unidade do mundo objetivo, a intersubjetividade do contexto que desenvolve suas vidas".

O processo de diálogo no coletivo, segundo os professores, tem sido uma constante aprendizagem, pois não existem verdades fechadas, saberes melhores que o outro. O grupo aprende, também, desde diferentes informações que ele mesmo gera, alimentando-se assim do saber que o coletivo constrói através da comunicação, do respeito às idéias do outro, aceitando que a pessoa possa ter um melhor argumento, e não deixando que haja processos de coerção no grupo para, assim, chegar a acordos "verdadeiros".

Considerando a trajetória do grupo e o desenvolvimento de ações construídas até o momento, este foi possível a partir de um processo de diálogo crítico e comunicativo. Para Núria, as 
coisas inicialmente não foram fácies, pois às vezes as pessoas tem que reconhecer e entender o que a outra está dizendo e não deixar-se levar por questões pessoais que acabam fechando ou dificultando o debate. Para Pérez Gómez (2000, p. 173)

Na cultura de colaboração existe espaço para o conflito e a discrepância, sempre que existam mecanismos de comunicação e entendimento que permitam a reflexão e o contraste construtivo, precisamente porque se parte de uma compreensão comum da educação e da comunicação humana como um processo aberto a diversidade e a criação, um compromisso ético com a pluralidade deformas de entendimento da realidade individual e social quando se comparte uma estrutura democrática e solidária.

No trabalho coletivo se deve reconhecer que o debate de idéias não é um conflito pessoal, onde se pode desconsiderar a idéia do outro. É em função do diálogo reflexivo racional, intentando potencializar e favorecer processos de interação entre todos os participantes, sem atitudes de coerção, é que se pode, de fato, validar uma construção coletiva, quer dizer uma racionalidade comunicativa que, segundo Habermas (1989a), está vinculada a capacidade reflexiva, crítica e cooperativa.

Neste sentido, existe a necessidade de estabelecer diálogos que sejam de fato ações reflexivas para que as pessoas possam entender criticamente, através da argumentação, as pretensões dos participantes. Para Boladeras (1996, p. 71-72), é "por esta via, obviamente, que a racionalidade é discursiva, ou seja, capacidade de argumentação e de estabelecer ações orientadas ao entendimento (entre diferentes indivíduos e do indivíduo consigo mesmo), discurso dos quais onde se da conta as pretensões de validez".

O que um coletivo busca, através de suas reflexões e intervenções, é validar suas ações, mas estas somente podem ser validadas e entendidas como coletivas sempre que os acordos não sejam coercitivos. Minha experiência junto a este coletivo, além do trabalho de campo onde pude aproximar meu olhar de maneira mais específica sobre esta questão, me permite dizer que, mesmo que o coletivo tenha dificuldades internas neste momento do trabalho entre as duas instituições, não existe atitudes de coerção para validar um ou outro argumentos.

Ayueste et al. (1999, p. 81-82), baseados na teoria da ação comunicativa de Habermas, apontam que a força argumentativa do debate sem coerções é a que valida as ações do coletivo. Para estes autores

Movimento, Porto Alegre, v. 10, n. 1, p. 157-179, janeiro/abril de 2004 
A perspectiva comunicativa supõe a aceitação de que ninguém tem a solução sobre o que, quando, e como ensinar e avaliar, mas que se pode ir construindo soluções provisórias, que podem ser melhoradas posteriormente, através de uma dinâmica inter subjetiva. (...) A ênfase é posta no diálogo, no intento de chegar a acordos mais universais possíveis de cada tema. Não se embasa no ilusório igualitarismo, nem em uma estéril conversação sobre qualquer coisa, mas sim uma democrática perspectiva que permanece aberta a que a argumentação de outros participantes melhores a própria perspectiva, por muita diferença que existe de posição ou de conhecimentos científicos.

Llüisa, que hoje ocupa um cargo de coordenadora da área de educação física na prefeitura, declara que

A grande maioria dos professores chegou a um grau de compreensão que não é qualquer "besteira" que alguém diz e as pessoas aceitam e tão pouco os professores se deixam levar por manipulações de quem seja. A experiência que tenho com este grupo, principalmente enquanto coordenadora, me permite dizer que os professores vão dando conta quando identificam que há manipulações, e ficam seriamente bravas.

Núria e Josep também declaram que em sua escola, a relação entre os professores de educação física não se dá porque um quer que seja e vai cooptando as pessoas de qualquer maneira.

Nós chegamos a um entendimento de que o respeito e a sinceridade são o que nos fez avançar em todos os sentidos, e se alguém não pensa dessa maneira já se identifica na hora, e o grupo busca mediar para não deixar influenciar no trabalho. Não é fácil, pois há questões pessoais que muitas vezes são muito fortes, mas o grupo vai sabendo bem como atuar com essas coisas.

Um aspecto interessante que surge no interior do grupo se refere ao medo de cometer erros. Os professores declaram que, inicialmente, isto era uma constante e foi preciso entender que, em um trabalho coletivo, os erros constituem um espaço de aprendizagem, mas que, este precisa ser identificado. Para Boladeras (1996), os processos de aprendizagem precisam argumentação para que seja possível ampliar e renovar a linguagem avaliativa e superar auto-enganos e dificuldades de compreensão.

Isto é o que evidência Llüisa,

Passei algumas experiencia interessantes no coletivo como por exemplo defender uma idéia que não é uma idéia fechada e alguém vem e argumenta muito melhor. Então pensava: será que estou equivocada! Na verdade não, somente não havia pensado daquela forma e reconhecia que o argumento do outro era melhor que o meu. Mas tenho que admitir que foi uma aprendizagem, pois no inicio, como não estava acostumada com essa prática, me sentia incomodada.

Movimento, Porto Alegre, v. 10, n. 1, p. 157-179, janeiro/abril de 2004 
Para o professorado, as atividades coletivas têm uma função muito especial, pois foi através das discussões que houve crescimento pessoal e profissional das pessoas e dos objetivos que perseguiam. Em um trabalho comunicativo, todos podem e têm algo com que contribuir; ninguém é dono da verdade; o saber deve se construído e validado no e pelo coletivo. Estes aspectos representam, para eles, a condição essencial para identificar que estão avançando criticamente na sua prática pedagógica. O que me leva a considerar que os professores estão repartindo e adquirindo um saber que eles imaginavam que não tinham. Para Gauthier et al. (1998, p. 339)

0 saber é, antes, o resultado de uma produção social e, enquanto tal, está sujeito a revisões e revalidações que podem, inclusive, chegar até a refutação completa. Além disso, a idéia de validação deve substituir a idéia de verdade. Por conseguinte um saber seria válido graças a sua capacidade de persuadir e não graças a um absoluto percebido como verdade.

Neste sentido, Núria declara

Sabemos que decidimos uma determinada ação, mas isto é uma decisão do grupo. Se não esteve bem não tem problema, vamos ver o que passou e ver criticamente como se pode fazer diferente e mudarmos. Não existe uma única maneira de fazer e ninguém tem uma proposta perfeita de como as coisas devem acontecer.

Para Josep

Não existe problema se nossas decisões forem insatisfatórias, o melhor é que podemos mudar, ou seja, se avalia e se começa outra vez. Dentro do grupo não existe a verdade de uma só pessoa, existe decisão do grupo depois de debater, se decide e assim, se não foi muito bem, pois se analisa e se mudar, sem nenhum problema. Como construímos juntos, assumimos as coisas, é assim que temos conseguido realizar alguma coisa na educação física.

Llüisa pensa que o importante é que as pessoas possam voltar a refletir sobre os argumentos e reconsiderá-los posteriormente, se for necessário, somente assim é possível conseguir garantir cada vez mais a participação crítica e democrática do grupo. Para ela, o coletivo deve proporcionar que as pessoas possam ter a oportunidade de rever seus próprios argumentos e dos demais participantes, para tomar as decisões e mudarmos se for preciso, mas somente é possivel através do diálogo. Na visão de Ayuste (1999, p.37.38), num "processo de discussão cabe a possibilidade de que os sujeitos mudem seus próprios significados em função do ato comunicativo e da auto-reflexão que ele comporta".

Movimento, Porto Alegre, v. 10, n. 1, p. 157-179, janeiro/abril de 2004 
Os participantes da investigação destacaram que um trabalho coletivo não significa a homogeneidade de idéias e tão pouco perder a individualidade, isto em um trabalho deste tipo, é impossível. O que existe é conflito mas é com o diálogo, o debate e o respeito aos argumentos e a heterogeneidade das vivências compartilhadas no cotidiano que o coletivo vai demarcando suas ações e construindo seus saberes. Saber este, que, segundo Fontana (2002) é construído através da mediação com outros saberes em momentos e contextos distintos, refletindo sobre o "que fazer" cotidiano.

Os professores percebem que em um trabalho coletivo é preciso que a pessoa, através do processo de diálogo, tenha a possibilidade de rever sua prática, voltar a refazer a planificação da organização de sua própria ação para construir saberes. Para Habermas (4989a), a ação comunicativa nos remete, na prática, a uma ordem social inacabada onde a interação humana pressupõe um discurso, porque somente a argumentação discursiva permite resolver tanto as problematizações como sua validez, assim como a legitimidade das normas estabelecidas.

Neste sentido, os professores valorizam muito o que aprenderam e consideram que o importante é conservar o debate irrestrito entre os participantes, pois somente assim se tem conseguido construir saberes.

O saber é uma atividade discursiva que consiste em tentar validar, por meio de argumentos e de operações discursivas (lógicas, retóricas, dialéticas, empíricas, etc) e lingüísticas, uma proposição ou uma ação. $O$ saber não se reduz a uma representação subjetiva nem asserções teóricas de base empírica, ele implica sempre o outro, ou seja uma dimensão social fundamentalmente, a medida em que o saber é justamente uma construção coletiva, de natureza lingüística, vinda de discussões, de intercâmbios discursivos entre seres humanos.

Levando em conta que o professorado se movimenta em função de uma objetividade que possa dar sentido aquilo que está fazendo, o trabalho coletivo exige uma tomada de posição que ao mesmo tempo representa a validez de um determinado saber. Neste sentido, a decisão definida pelo grupo passa a ser o critério de validade que, segundo Tardif (2002b, p. 197), não se "limita mais a adequação das asserções aos fatos, se não que passam antes pela idéia de acordos comunicativos dentro de uma comunidade de discussão".

Movimento, Porto Alegre, v. 10, n. 1, p. 157-179, janeiro/abril de 2004 
A experiência do professorado os permite reconhecer que, através do trabalho coletivo, é possível progredir em sua prática. Por isso, considerando a trajetória do grupo na construção de uma proposta pedagógica de educação física escolar, se pode dizer que foram os diversos consensos que proporcionaram e vem permitindo ao coletivo construir saberes pedagógicos, um saber que está em constante (re) elaboração e que para Gauthier et ai. (1998, p. 339).

É muito mais fruto de uma interação entre sujeitos, o fruto de uma interação lingüistica, inserida num contexto. Por isso mesmo, o saber remete a algo intersubjetivamente aceitável para as partes presentes. Além disso, a validade do saber varia de acordo com a natureza da relação com o mundo no qual os sujeitos se inserem. Finalmente, um saber terá valor a medida que permita manter aberto o processo de questionamento. Um saber fechado sobre si mesmo não passa de uma saber estático, dogmático, incapaz de alimentar a reflexão.

Neste sentido, posso considerar que o trabalho coletivo do professorado na construção de uma proposta para a educação física escolar, vem conseguindo uma forte "cultura colaborativa" que, segundo Hargreaves (1999), ocupa um lugar central para a elaboração e implementação de mudanças.

\section{Aprendizagem no trabalho colaborativo}

A partir da descrição realizada até o momento se pode evidenciar que trabalhar colaborativamente é uma tarefa difícil, mas necessária quando se deseja mudanças educacionais que de fato tenham uma relevância qualitativa. Considerando que um trabalho colaborativo é uma atitude que se aprende e que o saber é uma construção social, não se pode deixar de descrever também que o saber dos professores está representado por suas experiências anteriores, sejam profissionais e pessoais, e que essas influenciam fortemente, "positiva e negativamente" na construção das relações colaborativas.

Assim que, as relações que os professores estabelecem com os saberes que estão sendo construídos, tem que ver com o contexto de sua socialização profissional. Ou seja, o saber do professor traz a marca de seu trabalho, é a partir de esta relação que ele o produz, o organiza e o compõem. Entender este fato significa para Tardif (2002b, p. 343), reconhecer que o saber dos professores é um saber social e, enquanto tal, estes se "apoiam e dependem diretamente das condições sociais e históricas nas quais exercem sua profissão. Os saberes dos professores somen- 
te podem ser compreendidos na relação com as condições que estruturam seu trabalho. A questão dos saberes não pode, assim, ser separada da questão do trabalho".

Ao tratar esta temática junto aos professores, eles admitem que as experiências pessoais, de fato, influenciam, suas ações junto ao coletivo e isto representara para Llüisa um colocar em prática de sua formação pessoal e para Josep um duro, mas significativo aprendizagem. Suas declarações apontam respectivamente que

Eu vejo que essa metodologia de trabalho é um crescimento em um tempo individual e coletivo e creio que isso é muito importante para nós, eu creio muito no trabalho coletivo. Creio que é porque eu venho de uma família de onze irmãos, então ou éramos coletivos ou não iríamos sobreviver. Então eu aprendi isso com a vida e agora tenho a oportunidade de viver isso na educação física.

Eu sempre fui muito individualista. Em minha experiência no curso deformação e depois quando comecei a trabalhar sempre fazia eu mesmo minhas coisas. E isto me converteu em uma pessoa centralista. A pesar do trabalho com o grupo, ter sido de certa maneira um impacto, utilizei uma coisa que aprendi na minha formação familiar que é escutar, isso me ajudou muito no inicio. Tu não vai acreditar, mas fiquei quase um ano no grupo basicamente escutando, fazia poucas intervenções porque a lógica do trabalho coletivo era outra diferente da experiência que tive. Como isto já é público e reconhecido por todos do grupo e eu tenho essa consciência, o próprio coletivo já pode me cobrar e não me sinto incomodado ou chateado por isso. Além disso, foi uma aprendizagem e hoje posso dizer que o Josep da escola e o Josep da casa é a mesma pessoa.

Essas duas experiências mostram que não é possível dissociar a pessoa de sua experiência e situação de trabalho. Essas são sempre compartilhadas nos espaços sociais de convivência, neste caso a escola. Para Gauthier et al. (1998, p. 343-344)

De fato, todo professor, como membro de uma sociedade e de uma comunidade específica, dispõe de saberes compartidos igualmente por seus concidadãos. Além disso, possuem saberes que são próprios em virtude de sua experiência de vida pessoal. Estes saberes, que chamaremos de "culturais e pessoais" exercem um papel na prática docente. Mesmo sendo adquiridos fora do exercício da profissão, podem ser manipulados para fins específicos para o ensino. Isto é o que ocorre com todo trabalho humano, pois os conhecimentos dos trabalhadores são sempre muito mais amplos que aqueles estritamente necessários para a tarefa a ser a realizada.

Os professorado chegou a um grau de maturidade e compreensão que dizem que hoje o que mais interferem ou dificulta o trabalho coletivo são as mudanças políticas estruturais sem a prévia consulta e reflexão crítica sobre os fatos. Segundo Llüisa,

Movimento, Porto Alegre, v. 10, n. 1, p. 157-179, janeiro/abril de 2004 
O que desanima muitas vezes no trabalho coletivo não é o fato de que alguns professores não querem participar, pois sabemos que o trabalho pode caminhar, como tem sido até agora. Já sabemos que não são todos os que atuam com esta perspectiva, mas través da prática e do diálogo se pode conseguir. O que desanima são as mudanças políticas que vem de cima para baixo que terminam com os espaços coletivos de encontros entre os professores.

Como já disse em um outro momento deste artigo, os professores estão convencidos de que a criação de estruturas que valorizem as organizações do tempo e do espaço do professora-do, em relação aos espaços de discussão, é fundamental para uma aprendizagem coletiva.

A partir destas reflexões, aponto que a maior dificuldade que esses professores tem enfrentado no desenvolvimento do trabalho coletivo, não se refere somente aos seus desejos, mas principalmente ao apoio institucional que também possa facilitar essa organização coletiva dentro do centro educativo.

Concretamente pude perceber tanto no trabalho de campo como nos documentos de "Ajuda Memória", que o momento no qual os professores mais construíram coletivamente seus sabe-res, foi quando criaram outros espaços de reflexões e debates. Dessa forma, percebo que são as mudanças administrativas e a pouca clareza de uma política educativa que dificultam as ações coletivas dos professores.

Considero que as estruturas são fundamentais para este tipo de trabalho, ainda que não determinem a construção coletiva. Por outro lado, percebo que a ausência de essas estruturas não colabora e tão pouco propicia uma cultura que permita o trabalho coletivo.

Neste sentido, posso intuir que a falta de outros espaços de trabalho coletivo pode estar contribuindo para que um professor se desinteresse e/ou seja desprovido de responsabilidades frente a um projeto pedagógico, podendo decorrer daí, uma ausência de sentido e significado de sua ação educativa.

Por outro lado, a experiência tem demonstrado que a partir do trabalho coletivo e colaborativo, os professores tiveram a oportunidade de aprender uns com os outros, o que me permite também refletir que o saber, enquanto processo argumentativo, co-municativo e social é de fato uma construção coletiva. Para os professores esse saber se caracteriza por vários aspectos, a saber:

Movimento, Porto Alegre, v. 10, n. 1, p. 157-179, janeiro/abril de 2004 
a) os professores perceberam que com o trabalho coletivo foi possível progredir nas suas práticas cotidianas na perspectiva que eles desejavam e que isso valorizou o que eles faziam. Isso tem lhes fortalecido enquanto coletivo para reivindicar outros espaços para se organizarem;

b) permitiu que se aproximassem de sua profissão e entendessem como esta se configura historicamente e as relações compartidas no trabalho, como uma forma de superar o isolamento com que trabalham na escola;

c) o cotidiano da escola e as relações internas de poder muitas vezes criam distâncias de outras possibilidades de diálogo com os próprios pares e com os demais professores. Foi dentro desta discussão e deste debate sobre o que fazer que o saber pedagógico tem sido refletido e construído. Segundo Pérez Gómez (2000, p. 173), "a cultura de colaboração é tão complexa e difícil como o próprio processo educativo, não só porque é difícil praticar dentro da cultura tradicional dos docentes, escassamente familiarizada com a cooperação (...) senão fundamentalmente porque sua natureza ética implica a inevitável diversificação de suas interpretações, em virtude dos interesses dos diferentes grupos de poder que se inseridos sobre a vida da escola";

d) este caminho proporcionou aos professores a possibilidade de serem menos dependentes das regras institucionais e teóricas, de construírem sua autonomia e de adquirirem mais segurança nas decisões sobre as ações, apoiadas nos saberes de suas experiências de trabalho docente. Neste sentido, Pérez Gómez (2000, p. 173) afirma que "a cultura da colaboração é o substrato básico intelectual e afetivo para afrontar a incerteza e o risco do fracasso. A incerteza, o fracasso e o conflito não são conseqüências indesejáveis no processo de mudanças e aprendizagem, senão seus companheiros inevitáveis, sempre que o processo de aprendizagem individual ou social for o suficientemente rico e relevante para afetar parcelas fundamentais da vida individual e coletiva";

e) superar a fragmentação e o isolamento pedagógico somente foi possível com o trabalho de colaboração e pelo processo de desenvolvimento entre eles, de uma paciência histórica (como eles mesmos chamam essa trajetória). Ainda que o processo seja complexo e cheio de incerte-

Movimento, Porto Alegre, v. 10, n. 1, p. 157-179, janeiro/abril de 2004 
zas, em última instância o desejo sempre foi o de aprender a conviver e transformar a realidade, respeitando e valorizando as diferenças individuais e coletivas. Como disse Fontana (2000, p. 77), o trabalho coletivo é um espaço para discutir "nossos saberes e sobre nossos não saberes". No coletivo se aprende desde estas duas perspectivas;

f) o intercâmbio de informação, de experiências, de saberes no interior do grupo é o que possibilita uma interlocução com o saber do outro e faz com que o saber acumulado não seja um saber individual de uma única voz. São as diversas vozes que fazem com que este seja gerado;

Nesse sentido, com a reflexão realizada até o momento fica evidenciado que o trabalho coletivo e colaborativo foi uma atitude fundamental para concretizar algumas transformações educativas que se desejava no PCTP. Na descrição desta perspectiva colaborativa vejo como pertinente assinalar a contribuição autores como de Hargreaves (1999, p. 270) no sentido que "na colaboração (...), o verdadeiramente importante é quem a controla, quem participa nela, qual são suas finalidades e que condições são necessárias para esclarecê-la e mantê-la".

Este autor, em uma de suas investigações realizada junto a uma escola, aponta onze princípios positivos do trabalho colaborativo que surgiram como "resposta a um mundo onde os problemas são imprevisíveis, as soluções não são evidentes e as demandas e expectativas se intensificam". Sua contribuição, da qual compartilho minhas reflexões, reforçar bem a relação entre assessor e professores e sintetiza a experiência que vem se vivendo em na Uberlândia na organização do trabalho coletivo. Por outro lado, vem também confirmando que o processo de construção de saber neste grupo não partiu de verdades prontas, como receitas mágicas para resolver problemas da prática, mas sim de princípios que segundo Hargreaves (1999, p. 269-270) se apresentam caracterizados como:

a) Apoio Moral - A colaboração reforça a definição de solução, permite que os aspectos vulneráveis sejam explicitados e se ponham em acordo além de ajuda que as pessoas superem os

Movimento, Porto Alegre, v. 10, n. 1, p. 157-179, janeiro/abril de 2004 
fracassos e frustrações que acompanham as mudanças em suas primeiras etapas que, em outro caso, os sufocariam e os impediriam de avançar;

b) Aumento da eficiência - A colaboração elimina as duplicações e a redundância entre professores e disciplinas dado que as atividades se coordenam e são compartilhadas as responsabilidades;

c) Melhora da eficácia - A colaboração melhora a qualidade da aprendizagem dos alunos ao melhorar a qualidade do ensino dos professores. Também estimula a assumir riscos, a uma maior diversidade de estratégias docentes e a uma sensação de maior eficácia entre os professores, dado que os estímulos positivos e a retroalimentação sobre as conseqüências das ações, fortalecem a confiança em si mesmos. Todas estas coisas influem e facilitam a aprendizagem dos alunos;

d) Redução do excesso de trabalho - A colaboração permite compartilhar as cargas e pressões que se derivam de umas demandas de trabalho intensificadas e do câmbio acelerado, de maneira que cada professor e cada líder não tenham por que carregar com tudo sozinho.

e) Perspectivas temporais sincronizadas - A colaboração reduz as diferenças de perspectiva temporal entre os administradores e os professores. A participação em atividades comuns e a comunicação criam umas expectativas comuns e reais em relação às linhas de desenvolvimento temporal do câmbio e a implementação. Os mesmos princípios se aplicam também à sincronização das perspectivas e expectativas temporais entre professores e alunos quando se convertem em co-participantes do processo de aprendizagem;

f) Certeza situada - Os dois piores estados do conhecimento são a ignorância e a certeza. A colaboração reduz a incerteza e limita o excesso de culpabilidade que, no caso contrário invade a docência, ao fixar de comum acordo uns limites sobre o que prudentemente possa ser conseguido em qualquer ambiente. A colaboração cria também uma confiança profissional coletiva que pode ajudar os professores a resistirem à tendência de depender de falsas certezas científicas sobre a eficácia 
docente, a eficácia das escolas e similares. A colaboração suplanta as falsas certezas científicas ou as débeis incertezas ocupacionais pelas certezas situadas da sabedoria profissional coletiva das comunidades dos professores;

g) Assertividade política - A colaboração, na suas formas mais intensas, capacita os professores para interatuar com maior confiança em si mesmos e maior assertividade com os sistemas que os rodeiam e a multiplicidade de inovações, mais ou menos razoáveis, que delas se derivam. A colaboração fortalece a confiança para adotar inovações procedentes do exterior, a prudência necessária para retrasar sua adoção e a força moral para opor-se a elas. Nesse sentido, também alivia os efeitos da intensificação e a sobrecarga antes mencionada;

h) Maior capacidade de reflexão - A colaboração no diálogo e na ação constituem uma forte fonte de retroalimentação e de comparação que incita os professores a refletirem sobre suas próprias práticas. Os outros se convertem em espelhos para a própria prática, levando a uma reflexão sobre ela e a sua reformulação com um sentido mais crítico;

i) Capacidade de resposta de organização - A colaboração reúne conhecimentos, habilidades e capacidades dos professores, permitindo-lhes responder com vigor as diversas limitações e oportunidades do entorno, a examinar de maneira pré-ativa o ambiente em relação às mudanças que estão por vir e a descobrir as oportunidades que possa oferecer.

j) Oportunidades para aprender - A colaboração incrementa as oportunidades dos professores para aprenderem uns com os outros entre aulas, entre departamentos e entre escolas. A colaboração constitui uma poderosa fonte de aprendizagem profissional, para realizar melhor a tarefa cotidiana. Nas organizações cooperativas, a totalidade é maior que a soma de suas partes;

k) Aperfeiçoamento contínuo - A colaboração estimula os professores a não contemplarem as transformações como uma tarefa que termina, mas sim como um processo sem fim de aperfeiçoamento contínuo em uma busca constante da máxima excelência, por uma parte, e de novas soluções aos pro-

Movimento, Porto Alegre, v. 10, n. 1, p. 157-179, janeiro/abril de 2004 
blemas que surgem com maior rapidez cada vez, por outra. Pela sua forma de promover a reflexão compartilhada, a aprendizagem profissional e a acumulação de saberes e destrezas de todos, a colaboração constituem uma premissa fundamental para a organização educativa.

Orientación del trabajo colaborativo en la construcción del saber docente: la perspectiva de la planificación colectiva del trabajo pedagógico (PCTP)

Resumen: Este estudio busca describir la construcción de

algunas acciones orientadoras en la construcción de un trabajo colectivo en el interior de un proyecto de formación permanente para profesores de educación física de la enseñanza pública en la cuidad de Uberlândia, Minas Gerais, Brasil, denominado de Planificación Colectiva de Trabajo Pedagógico (PCTP). La metodología esta caracterizada como un estudio de caso del tipo etnográfico. El estudio apunta que siendo la construcción del saber, a través de un proceso colaborativo, una dimensión social está se materializa a partir de intercambios intersubjetivos y discursivos siendo necesario una interlocución irrestricta con las diferentes voces que componen tal proceso. Palabras-clave: Construcción del Saber, Trabajo Colectivo, Formación Profesional.

\footnotetext{
Orientation for the construction of the knowledge of the teaching staff collaborative work: the perspective of the pedagogic work gruoup planning (PWGP)

Abstract: This study searches to describe the construction of some guided actions in the construction of a collective work inside a project of permanent formation for physical education teachers of the public education in Uberlândia schools, Minas Gerais, Brazil named of Collective Planning of the Pedagogic Work (CPPW). The study aims that being the construction of knowledge, across a social and colaborative process as
} 
a dimension that materializes from intersubjective and discursive exchanges necessary in a dialogue irrestricta with the different voices that compose such a process. Keywords: Construction of Knowledge, Collective Work Professional Formation.

\section{Referências}

ALVES, M. V. R; ANTUNES, M. F. SOUZA; SOUSA, K. C. S. e SILVA, M. A Handebol Escolar. In: MUÑOZ PALAFOX, G. H. (Org.) Planejamento Coletivo do Trabalho Pedagógico-PCTP: A experiência de Uberlândia. Uberlândia: Linograf Editora e Arte, 2002. p. 151-156.

AYUSTE, A.; FLECHA, R.; LOPES PALMA, F. e LLERAS, J. Planteamientos de la pedagogia crítica. Comunicar y transformar. Barcelona: Graó, 1999.

BOLADERAS, M. Comunicación, ética y política. Habermas y sus críticos. Madrid: Editorial Tecnos, 1996.

BOUFLEUER, J. R. Pedagogia da ação comunicativa: una leitura de Habermas. ljuí: Editora Unijuí, 1998.

ELLIOTT J. La Investigación-acción en educación. Madrid: Morata, 1990.

FONTANA, R. A. C. Como nos tornamos professoras? Belo Horizonte: Autentica, 2002

GADOTTI, M.. Pensamento Pedagógico Brasileiro. São Paulo: Ática, 1987.

GAUTHIER, C. et al. Por uma Teoria da Pedagogia: pesquisas contemporâneas sobre o saber docente. Ijuí: Editora Unijuí, 1998.

HABERMAS, J. Consciência Moral e agir comunicativo. Rio de Janeiro: Tempo Brasileiro, 1989a.

HABERMAS S, J. Teoría de la acción comunicativa: complementos y estudios previos. Madrid: Cátedra, 1989b.

HARgReAVES, A. Profesorado, cultura y postmoderno. Cambian los tiempos, cambia el profesorado. Madrid: Morata, 1999.

MUÑOZ PALAFOX, G. H. Intervenção político-pedagógica: a necessidade do planejamento de currículo e da formação continuada para a transformação da prática educativa. Tese de Doutorado - Pontifícia Universidade Católica, São Paulo, 2001.

PÉREZ GÓMEZ, A. I. La cultura escolar en la sociedad neoliberal. Madrid: Morata, 2000.

Movimento, Porto Alegre, v. 10, n. 1, p. 157-179, janeiro/abril de 2004 
SILVA, M. H. N.; MOURA, M. A. S. e AMARAL, G. A. Jogo e Aprendizagem sócio-crítica. In: MUNOZ PALAFOX, G. H. (Ogr). Planejamento Coletivo do Trabalho PedagógicoPCTP: A experiência de Uberlândia. Uberlândia: Linograf Editora e Arte, 2002. p. 96-99. TARDIF, M. Saberes docentes e formação profissional. Petrópolis:Vozes, 2002.

TERRA, D. V. Ensino crítico-participativo das disciplinas técnico-desportivas nos cursos de Licenciatura em Educação Física: análise do impacto de ensino no Handebol. In. COSTA, V. L. M. (Org.) Formação Profissional Universitária em Educação Física. Rio de Janeiro: Editora Central UGF, 1997. p. 201-232.

Recebido em: 09/01/2004 Aprovado em: 29/01/2004

Dinah Vasconcellos Terra Rua Arlindo Gomes Rodrigues, 1239 Bairro Santa Mônica, Uberlândia/MG 38408-264 e-mail: $\underline{\text { dvterra@wanadoo.es }}$

Movimento, Porto Alegre, v. 10, n. 1, p. 157-179, janeiro/abril de 2004 